\title{
Economics' Wisdom Deficit and How to Reduce It
}

\author{
John F. Tomer, Manhattan College, NY
}

\begin{abstract}
As is well understood, the values inherent in the dominant neoclassical economic paradigm are selfinterest and optimisation. These are the values that guide individuals and policymakers in advanced capitalist economies in their economic decision making. As a consequence, the economics discipline, arguably, is insufficiently oriented to helping people and organisations make wise choices, choices about what is really and truly in people's best interests. In other words, there is strong reason to believe that economics has a wisdom deficit.

This paper draws on great philosophers such as Aristotle to explain what wisdom is and why, although economics is concerned with the normative aspect of decision making, economics has too infrequently been used to help people or their societies make wise decisions. This paper is also concerned with how a society's economic decision-making processes can be improved in order that these processes incorporate a much greater dose of wisdom. One relevant question here is: can we learn with the help of philosophers, psychologists and organisation researchers how to make economic decisions that apply the practical wisdom that Aristotle advocated?

This paper's overall purpose is first to point the way toward greater decision-making wisdom, and second to propose one method for improving the wisdom of important economic-related decision making. Hopefully, this paper will serve to put the issue of decision-making wisdom higher on the agenda of economists and, as a consequence, lead to wiser decisions in the economic sphere, thereby reducing the wisdom deficit.
\end{abstract}

\section{Introduction and Purpose of Paper}

Richard Thaler (2015, p. 345) likes to use the phrase 'nudge for good'. He points out that nudges are merely tools that have the potential to help people become better off. But he also points out that people can be nudged by businesses or governments with bad intentions, and that can lead to outcomes that are not good for them. Naturally, he hopes the latter will not happen and that nudges will only be used for good. If economists were advising on what nudges to use, would they have the wisdom to recommend only good nudges, and more generally, only good government programs? There is reason to believe that, given the values inherent in the dominant neoclassical paradigm and even the main strands of behavioural economics, economists may too often give unwise advice about these matters. The economics discipline, it seems, is insufficiently oriented to helping people and organisations make wise choices, choices related to what is really and truly in people's best interests. In other words, there is strong reason to believe that economics has a wisdom deficit.

This paper explains what wisdom is and why, although economics is concerned with decision making, particularly the normative aspects of decision making, economics has too infrequently been used to help people or their societies make wise decisions. In other words, economics is insufficiently oriented to helping people make decisions that are really right and best for them. Economics has mainly been oriented to helping people make decisions that enable them to get more of what they happen to want or desire most. 
This paper is also concerned with how a society's economic decision-making processes can be improved in order that these processes incorporate a much greater dose of wisdom. One relevant question here is: can we learn how to make economic decisions that apply the practical wisdom that Aristotle advocated? Obviously, attempting to change the way societies make decisions so that their decisions will reflect wisdom would be a huge task, one which is largely beyond the scope of this paper. The goal of this paper is more modest. This paper's purpose is first to point the way toward greater decision-making wisdom, and second to propose one method for moving in this direction. Clearly, people would be much better off if they and their organisations and societies could learn how to make wiser economic decisions at least on the most important matters. Hopefully, this paper will serve to put the issue of decision-making wisdom higher on the agenda of economists and, as a consequence, lead to wiser decisions in the economic sphere.

\section{Differing Views on How Economic Choices Are or Should Be Made}

\section{Neoclassical Economics: Normative and Descriptive Decision Making}

To consider how economic choices might be made more wisely, it is first necessary to consider carefully the two different contemporary views regarding how consumer choices are or should be made. First is the neoclassical economics (NE) view, also referred to here as the standard economics or mainstream economic view. The essence of the normative NE view is that rational choice involves optimisation. This means that consumers should choose to purchase the set of goods that will maximise their utility (see, for example, Yuengert, 2012, pp. 14-19). Using mathematics, neoclassical economists represent this as: Maximise $U(X)=$ $\mathrm{U}\left(\mathrm{x}_{1}, \mathrm{x}_{2}, \ldots\right)$. This means choose the consumer goods, $\mathrm{x}_{\mathrm{i}}$, that maximise $\mathrm{U}$ (utility) subject to the condition that the sum of one's expenditures on goods must be less than or equal to the individual's income $(Y)$. In other words, where $p_{i}$ is the price of good $i$, the sum of expenditures $\left(p_{1} x_{1}+p_{2} x_{2}+\ldots\right)$ cannot exceed $Y$. NE's positive (or descriptive) view of how people behave is exactly the same as the normative view. Note that a more complete version of the NE model of consumer choice would include such factors as uncertainty, resource endowments, multiple time periods, possible constraints, and strategic considerations. It is also important to note that according to $\mathrm{NE}$, people behave in an entirely self-interested manner; they derive maximum utility or satisfaction from whatever goods they want or desire. Within NE, there is no attempt to question the substance or legitimacy of the goods people desire and acquire.

\section{Psychological Economics: Normative and Descriptive Decision Making}

Next let's consider psychological economics (PE), the strand of behavioural economics deriving from the research of Kahneman and Tversky. The normative view of PE is basically the same as the normative view of NE. NE and PE both assume that the goods people should acquire are what people want or desire, i.e., what they prefer; these are the things that give them the most utility or satisfaction. PE, however, departs substantially from NE with regard to the descriptive aspect of economic theory (Heukelom, 2014, pp. 98-111; Kahneman, 2011, pp. 14, 271-272). In the PE view, people making choices are understood to often choose in a way that does not maximise their utility. Based on the careful observation of people's choice behaviour by practitioners of $\mathrm{PE}$, it is clear that people frequently choose in line with psychological and other supposedly irrelevant factors. Consequently their choices are 'irrational', i.e., not optimising. Because of their 'biases', people do not choose the NE 
optimum. Thus people's lives do not go so well, at least not as well as might be predicted by NE.

To the extent that the actual outcomes of humans' decision making consistently depart from the NE optimum in certain kinds of situations, provides strong support for the realism of PE's depiction of choice behaviour. Practitioners of PE have studied such behavioural regularities as the status quo bias, confirmation bias, and other biases due to inertia, anchoring, the endowment effect, loss aversion, the effect of strong emotions and many others. It is due to such factors that human decision makers are generally unable to make decisions that are consistently optimal. The upshot is that there are good reasons to believe that the descriptive version of PE provides a much more realistic understanding of human decision-making behaviour than NE does. But PE suffers from the same problem as NE on the normative side.

\section{The Problem with Economics' Normative View of Decision Making}

As indicated above, there is no doubt that PE by virtue of its realism improves upon NE in regard to the descriptive aspect of decision making. However, the normative aspect of PE (and NE) is arguably flawed. Let's consider some of the reasons for this judgment. At the heart of the matter, of course, is NE's normative conception that people should simply choose in an optimising way whatever it is they desire, i.e., whatever gives them utility. What is missing from the normative version of NE (and also PE) is the idea that ideal decision making should reflect acquired knowledge and wisdom. If people make decisions based only on what they are feeling or desiring, i.e., making their decisions only on the basis of their actual preferences, it seems unlikely that these decisions will be good decisions either for themselves or for their society. As Rescher points out,

'many of us do what we desire or want, but such actions may not be in our best interests or real interests .... Unless there are good reasons for doing so, ... [such actions] will not be what is really best for us' (Rescher, 1988, p. 5; as quoted in Tomer, 2008, p. 1704).

'Certain preferences are absurd - preferences which wantonly violate our nature, impair our being, or diminish our opportunities' (Rescher 1988, p. 95 as quoted in Tomer 2008, p. 1704).

And as Frank Knight, long ago, recognised, 'what the commonsense individual really wants is not satisfaction for the wants he has but more and better wants' (as quoted from McPherson 1984, p. 237 in Tomer, 2008, p. 1705).

To better understand PE's (and NE's) problem with normative decision making, it is necessary to understand the distinctions between three types of preferences (Tomer, 2008, pp. 1705-1706). The first, actual preferences, are the preferences that we are all familiar with; they are the preferences that reflect our wants and desires when we make ordinary choices among alternative goods. The second type of preference, metapreferences, are one's preferences about one's actual preferences. Metapreferences reflect our capacity to stand in judgment of our actual preferences. For example, we may have an actual preference for very sweet food, but we may prefer not to have that actual preference. The third type of preference is our true preferences. True preferences are our preferences for what is really right and best for us. True preferences are the preferences we would have if we were perfectly informed, unbiased and logical about what is really good for us. Consider our true preferences for a 
category of food, say vegetables. Our true preferences for a vegetable would presumably be a preference for a vegetable with the most healthful and nutritious qualities possible (Tomer, 2008 , p. 1706). Another example is that people might have a true preference for a diet that is extremely high on immunity to all forms of cancer. Note that, unlike the case for actual preferences and metapreferences, we may be partially or completely lacking in knowledge of our true preferences. People, for example, may not know their preferences in regard to what kinds of food they need to eat more of in order to improve their health. This lack of knowledge is an important reason why it is typically difficult for people to make choices that enable them to obtain what is really right and best for them. Another reason for people's difficulties making choices is psychological; recall the biases mentioned earlier.

\section{Choosing in an Ideal Normative Manner}

What does the above mean for choosing goods in an ideal, normative manner? In my view, the essence of normative rationality means that we should choose in accord with our true preferences; we should choose only goods that are truly right and best for us. Correspondingly, it means we should not settle on choosing goods that happen to appeal to us at a particular point in time but on reflection are not really right and best for us. Choosing only goods aligned with our true preferences, or at least mostly these goods, should reliably lead us to a high level of well-being (not simply our utility or welfare). Although making such truly rational choices is something that all of us can aspire to, it is not something that most of us can be expected to do, at least not regularly. That is because the ordinary person typically lacks the knowledge, unbiased insight and wisdom to do this.

\section{Choosing Ideally Implies Choosing Wisely}

As indicated above, true preferences are the preferences we have for goods that are very good for us. They are also the preferences that we would have for these goods if we had attained a high degree of wisdom. Let's consider the meaning of wisdom. Wisdom, as typically defined, 'is the ability to think and act using knowledge, experience, understanding, common sense, and insight... in a mature manner' (Wikipedia). To fully appreciate what wisdom means, it is important to take into account that wisdom has quite a few different connotations as indicated in the following definitions of wisdom:

1) Wisdom is the capacity of judging rightly in matters relating to life and conduct (Oxford English Dictionary);

2) Wisdom involves the understanding of causes, i.e., knowing why things are in a certain way (Aristotle, Metaphysics);

3) A person becomes wise when he/she can see what needs to be done and can do it successfully without being told what to do (Inuit tradition);

4) Wisdom involves coordination of 'knowledge and experience' and 'its deliberate use to improve well-being' (Peterson and Seligman, 2009, p. 106);

5) Wisdom involves superior ability to understand the nature and behaviour of things, people, or events (B. Legesse et al., in Encyclopedia of Human Behavior, $2^{\text {nd }}$ Edit., Academic Press, 2012);

6) Wisdom is the ultimate truth of things found in the heart of every religion;

7) In Buddhism, wisdom involves 'seeing things as they are' and gaining 'a penetrating understanding of all phenomena'. 
When one acts wisely in consumption activity, an individual is acquiring and using goods in a way that is consistent with his/her true preferences. Wise consumption contributes to one's well-being because it does not involve compulsive behaviour, it is not associated with pathologies, and it does not have other harmful effects. A person's wise consumption contributes to his/her physical, mental and spiritual health, and thereby, it contributes positively to at least some aspects of one's human development (Payutto. 1998, pp. 33, 42). The upshot is that the wise activities that advance one's human development will add to a person's or a society's well-being.

\section{Decision Making and the Wisdom of Aristotle}

\section{Aristotle's Decision Making Wisdom Compared to the Perspective of Neoclassical Economics}

To fully appreciate what wisdom is and what wisdom can contribute to decision making, one needs to read Aristotle's Nicomachean Ethics (see, for example, Kaplan, 1958). At the heart of Aristotle's philosophy is the view 'that people, when they act, are aiming at something they think is good' (Yuengert, 2012, p. 1). That is, when people make decisions they aim at some ultimate good such as a desirable quality of life, which is not a material item, but which is something that they believe will make them happy. Although both Aristotle and modern economists agree that 'people have objectives they seek to achieve,... the Aristotelian account of human behaviour is much richer than the maximisation of utility subject to constraints' (p. 1). Clearly, the Aristotelian depiction of decision making 'does not exhibit the mathematical exactness of an economic model', but it makes up for that in its comprehensive vision of how people make decisions as well as its lack of economics' typical simplification ( $p$. 1).

The Aristotelian approach to decision making is in many other respects quite different from NE. For example, the Aristotelian approach, in contrast to neoclassical economics, does not focus much on observable aspects of choice; it is focused on what happiness is (Yuengert, 2014a, p. 1). Compared to NE, the Aristotelian approach to the world is mysterious, less elegant, more uncertain, socially embedded, character-driven and fraught with meaning (pp. 2-4). Practitioners of the Aristotelian approach to decision making, more so than modern economists, mindfully consider both how people are and the nature of the decision-making environment. As a consequence, Aristotelians understand that there are limits to the usefulness of economic modelling. From a normative standpoint, the most important difference between rational economic decision making à la NE and Aristotelian decision making is that NE practitioners seek to explain human choices; whereas the Aristotelian approach generally aspires to gain wisdom about humans and their decision making.

\section{Aristotle's Practical Wisdom Concept}

For Aristotle, the key factor that explains the quality of a person's decision making is practical wisdom (PW). PW is the virtue or capacity by which a person acts well in the world (Yuengert, 2014b, pp. 4-5). PW is especially important in situations where the problem or policy under consideration is crucially important and difficult to formalise. PW is a quality that cannot be modelled or be fully formulated. Not surprisingly, it is a quality that gets left out of the analyses of NE economists when they simplify for purposes of analysis. NE, thus, does not consider the PW factor or for the most part other non-calculative skills and virtues that 
would enable a person to make important, high quality decisions. In general, the NE approach is too abstract and impersonal to enable it to appreciate a person's life and its flourishing, factors which may be important with respect to policy decision making. It is particularly important to consider PW when there are complicated relationships between instrumental goods and ultimate goods (p. 6). In complex situations, the needed PW may include selfmanagement strategies and other personal qualities (p. 7). According to Aquinas (1948), among the important virtues included in the PW factor are memory, docility, understanding, foresight, circumspection and constancy (p. 8). These PW qualities are the kind that develop over a lifetime as they are 'passed from person to person, not as one passes a book of instructions from hand to hand, but as one learns a craft, a way of life, through imitation and apprenticeship' (p. 8). The 'practically wise person is much more than a means-ends optimiser' (pp. 8-9). A person strong in PW is capable of 'reasoned judgment which brings into play experience and a wide range of non-calculative habits of perception and selfmanagement' (p. 9). Clearly, PW 'cannot be captured by the [NE] logic of optimisation subject to constraints' (p. 9).

\section{Religious Views and True Preferences}

The essence of the idea of true preferences and that people should try to act in accord with them can be found in the teachings of almost all philosophical, spiritual and religious organisations. These teachings are concerned with the gap between what a person wants and what is really best for the individual (Tomer, 2008, p. 1708). The latter ideal, our true preferences, 'are those we would have if we were closer to being the person we aspired to be'; they are our 'enlightened preferences' (p. 1708). Religions encourage us to develop ourselves fully, and therefore, to act in line with our true preferences. For example, according to Buddhist teachings, transforming our inferior actual preferences to our true preferences will provide us true happiness and enlightenment. This involves giving up one's materialistic or gross forms of pleasure for higher forms of pleasure (p. 1709). In this respect, Hinduism is very similar to Buddhism. According to Christian teachings, 'the spiritual input of Christ' is a key to achieving 'God's desired balance between self-interest and altruism in... decisionmaking situations' (Beed and Beed, 1999, p. 508), and consequently, behaving in line with Christians' 'moulded [or true] preferences' rather than their actual preferences. Islam also has teachings that correspond to the concept of true preferences. In their view, people could be 'motivated solely by the desire to maximise worldly pleasures' (their inferior actual preferences) (Biraima, 1998/1999, p. 212). Ideally, however, 'people [Muslims] could be in complete submission to God and be motivated solely by the desire to accumulate $2 \mathrm{good}$ deeds2 that yield thankfulness' (p. 213). Each religion teaches that inferior behaviour patterns (inferior actual preferences) should be given up in favour of ideal patterns reflecting one's true preferences, the latter leading along the path to God or enlightenment, and thereby, to longrun happiness. Another way of stating this is that each religion advocates that its members behave in accord with its version of wisdom.

\section{Wisdom and Human Development}

Wisdom is not something that humans are born with, but arguably humans have a capability for it and can develop it. Aristotle believed that everyone is capable of being wise (Schwartz and Sharpe, 2010, pp. 51-52). But it seems that relatively few people attain a high degree of wisdom. Further, it seems likely that the high level of wisdom of the relatively few is associated with the high level of maturity and human development progress these people 
have realised. Having a high level of human development (HD) involves much more than acquiring substantial cognitive capability and/or workplace skill. A person with a high degree of $\mathrm{HD}$ is one who has progressed along a multidimensional developmental path which includes social, psychological, emotional and biological dimensions (Tomer, 2017). Reaching a high level of HD generally occurs only when a person has benefited from a favourable environment, and thus, the person has had a good chance of developing many capabilities. When a person's environment has been unfavorable, however, such individuals have typically failed to negotiate certain stages of their development. In that case, the individual has likely gotten stuck or partially stuck at a certain developmental stage and failed to develop further without a special developmental intervention (p. 138). Note that the concept of HD used here draws on Abraham Maslow's humanistic psychological perspective, particularly his hierarchy of human needs. It is also informed by research on neurodevelopment as well as Ken Wilber's conception of how humans develop in an unfolding series of stages and levels. Further note that HD is usefully represented as a three-sided pyramid in which each triangular side represents a major developmental pathway. The three pathways are: 1) educational and cognitive development, 2) psychosocial and biological development, and 3) brain development (or neurodevelopment) (pp. 138-141). The upshot is that there is reason to believe that the people who have gained a great deal of wisdom are people who have lived long enough to have been able to take advantage of a significant number of the developmental opportunities that have been presented to them.

Research on the developmental stages of people's lives by Daniel Levinson and Erik Erikson can help us understand the universal patterns of people's lives and provide some insight regarding the progress of wisdom during one's life. Levinson (1978) in particular found that people's lives had both stable and transitional periods. He found that

'during stable periods, a person makes decisions and commits to building a life structure. During transitional periods, a person tends to review and evaluate the present structure ... to decide what aspects of their life to keep and what aspects to reject' (Tomer, 2017, p. 147).

Erikson's (1982) research on the developmental stages of adult life provides both similar and contrasting insights to those of Levinson. As an illustration, Levinson's theory regarding sequential developmental periods only weakly implies that a person's adult development follows an ascending path. Note that the existence of an ascending path would be consistent with the idea of growing wisdom with age. Erikson's research in contrast to Levinson's tends to strongly affirm ascendency. According to Erikson, full development of a person's life does not happen until middle to late adulthood (Tomer, 2017, pp. 148-149). This latter finding indicates that full development of wisdom does not occur until relatively old age. In interpreting these findings it is important to note that adult human development is generally not a smooth process; people often experience stressful episodes and periodic crises throughout their lives (Tomer, 2017, pp. 148-149). So although there is evidence of growing wisdom with age, one cannot be sure that this is true for every individual and during every stage of life.

As part of their human development, humans may develop virtues such as prudence, love of knowledge, courage, firmness, generosity, temperance and justice (Tomer, 2017, p. 149). Virtues are acquired capacities or dispositions that enable persons to contribute in some generic way with a high degree of excellence to activities that are challenging and important (McCloskey, 2006, p. 64; Roberts and Wood, 2007, pp. 60-64). Virtues are not specific, technical skills and do not involve performing specific roles such as managing a business or 
playing basketball. They are habits of the heart (McCloskey, 2006, p. 64), and they are deep, enduring settled character qualities that are formed by education in the broadest sense (Roberts and Wood, 2007, p. 69). Virtues enable humans to achieve excellence in some sphere of activity such as the interpersonal, the political or civic, the intellectual or the moral. Clearly the person who has developed a high degree of virtue has developed the capability for wise thinking and decision making at least in some sphere of life (Tomer, 2017, p. 150.

\section{The Essence of the Wisdom Deficit}

To understand the idea of a wisdom deficit, it is necessary to sum up the preceding analysis. At the heart of the matter is that both neoclassical economics and psychological economics rely on the same flawed normative view of decision making. According to that view, people ought to make decisions based primarily on what they want or desire, i.e., on the utility they expect to derive from anticipated decision outcomes. Clearly that is problematic. As argued earlier, people will be much better off if they make decisions leading to outcomes that are truly right and best for them, or for their organisations or for their society. These are the kinds of decisions that are based on very good reasons. Wise philosophers as far back as Aristotle knew this. Wise religious leaders know this. And many people who have attained a ripe old age, who have realised a high degree of maturity, and who have successfully met many developmental challenges along many HD pathways are likely to know this. Unfortunately, in countries like the U.S. in recent decades, too many economists, especially those who subscribe to the tenets of $\mathrm{NE}$, do not know this. As a consequence, too many poor decisions have been made because the decision makers have been either NE economists or have been under the overly strong influence of NE economists. Arguably, poor decisions have been made because the needed wisdom has not been applied in the decision-making process. In other words, there typically has been a wisdom deficit in important economic related decision making.

\section{How Can We Reduce the Wisdom Deficit?}

Obviously, if our society's decision making suffers from a wisdom deficit, we need to find a way to make the important decisions with a greater dose of wisdom. What is not immediately clear is how to do that. Although wisdom can be considered to be an input into a decisionmaking process, wisdom is certainly not a simple, tangible input that is easily inserted into any decision making process when decisions are being made. Wisdom is not a "'one size fits all' factor. What constitutes the relevant quality of the needed wisdom would seem to vary according to what is being decided and with other aspects of the decision-making context. In other words, the wisdom needed in important decision making does not have to be precisely the kind of wisdom that Aristotle had in mind or for that matter any other particular version of what constitutes wisdom.

What is essential in the process of adding wisdom to the decision-making process is that purely quantifiable economic considerations should not have paramount importance. The decision-making process cannot be a disguised version of optimisation, i.e., of maximising people's utility. The decision making processes that incorporate wisdom should make considerable use of non-economic, qualitative insights and concepts from philosophy, from the social sciences and from religions.

Suppose we are considering decision making related to large-scale projects in the public sector, say projects focused on problematic situations involving a substantial degree of socio-economic dysfunction. Suppose further that these kinds of decisions have in the past 
been made very unwisely. This poor performance might have been due to both poor decision processes and not having the participation of a sufficient number of wise people. Are there ways that societies can make these kinds of decisions differently and better? If so, making such a significant change in the decision-making process would involve learning how to utilise all the relevant knowledge and analysis related to the problem. It would also involve making decisions more wisely than in the past because it enables people and society as a whole to make choices that are really the best possible for all concerned. The next section makes a proposal for how such decision making can be accomplished more wisely.

\section{A Specific Proposal for Improving Decision-Making Wisdom}

In order to substantially increase the wisdom incorporated into economic decision making, an especially modified version of the Delphi method is proposed. Let's first consider the basic nature of and essential features of the typical versions of the Delphi method.

\section{How the Delphi Method Works}

The Delphi method (DM) takes its name from the Oracle of Delphi who according to ancient Greek myth could predict the future. The DM is a structured communication technique that has been used most notably for forecasting the future and for policy making. It has been especially useful in situations where the decision making is large and complex. Let's consider a generalizsed version of how the typical DM process works. Once a policy or issue has been identified, the first step in the DM process is choosing a facilitator. The first task of the facilitator is developing a series of questions related to the policy or issue, questions which are included in a questionnaire or survey. At the beginning of the first round of the DM process, the facilitator provides these questions to all the participants. The participants, also known as 'experts', are people who are chosen because of their relevant knowledge and experience regarding the topic. Note that at the very beginning of the process, the participant experts are invited to direct their attention to the overall problem or issue that they are seeking to understand. After considering the latter, the experts independently and anonymously reply to the facilitator's questions. This phase of the process is akin to brainstorming; its purpose is to produce a broad range of opinions.

In the second round, the facilitator will summarise the experts' first round replies. Based on these responses, the facilitator develops a second round of questions and provides these to the experts. During this second round, each expert again replies to the facilitator's questions. This typically involves revising and clarifying his/her first round judgments in light of the replies that all the other experts had made during the first round. The goal at this point is to clarify specific issues, remove irrelevant material, and look for common ground that would be the basis for a consensus. Subsequent rounds of communication between the facilitator and the experts follow in a similar manner. In this process, the facilitator and experts gradually hone in on areas of agreement until a consensus emerges among the experts about the problem or issue. The facilitator acts to control the feedback process, acting at each stage to identify and ease the gradual convergence of participant responses. The purpose of these multiple stepwise rounds of communication is to proceed until an acceptable level of consensus among the participants has been reached. The accepted consensus is considered the 'correct' answer or the solution to the problem. ${ }^{1}$ Finally, the result of the completed DM process is disseminated to the participants and other interested parties.

\footnotetext{
${ }^{1}$ The following online sources were used in writing this general description of the Delphi method: 1) 'Delphi Method', Wikipedia; 2) 'The Delphi Technique', Thangaratinam, Shakila and Redman, Charles
} 


\section{The Advantages of the Delphi Method}

Use of the Delphi method by governments and various types of organisations is no guarantee that the resulting solutions or answers will be successful. In some cases, use of DM has produced poor results (Wikipedia). Nevertheless, the DM is considered to be a 'widely accepted forecasting tool and has been used successfully for thousands of studies in areas varying from technology forecasting to drug abuse' (Wikipedia). There are a few important reasons why the DM can be expected to realise better results than conventional methods of analysis. Traditional methods typically involve the use of scientific theory along with quantitative models and trend extrapolation. In situations where there is a high degree of complexity and uncertainty, where there is controversy, debate or a lack of clarity, and where precise scientific laws do not exist, traditional methods have not worked very well. In general, the DM can achieve better results than conventional methods when there is no single true and knowable answer. What the DM is able to provide in contrast to conventional methods is analysis using informed, intuitive judgment

One notable advantage of the DM derives from its use of anonymous participant experts. Because the identity of the experts is not revealed to other participants, experts' opinions generally will not be influenced by other experts' authority, personality, attractiveness or reputation. Ideally, in a DM process, experts' opinions are only influenced by others' ideas, insights and analysis. The anonymity also minimises the 'bandwagon effect' and the 'halo effect'. Further, anonymity encourages free expression of opinions and open critique, as well as facilitating admission of errors when experts revise their judgments (Wikipedia). Note that in the DM, participants comment both on the responses of other individual experts and on the progress of the decision-making panel as a whole. Because of this, both individual participants' opinions and the facilitator's guidance role are given a useful challenge.

The DM is not a tool for making decisions; it is a policy analysis tool that can be used to help make decisions (Turoff, 1970, p. 154). In particular, the DM is an alternative to using the kinds of analysis that typically take place in conventional meetings and committees or that comes from using consultants (p. 153). Compared to conventional methods, the complex analyses of a Delphi usually involve a greater degree of intuitive interpretation and informed guesswork (Thanagaratinam and Redman, 2005, p. 120). A Delphi is particularly valuable because it brings people together across organisational lines and thereby gets all relevant views represented (Turoff, 1970, p. 152). The Delphi structure and sense of direction helps avoid 'often counterproductive discussions and digressions that bedevil face-to-face group discussions' (Thanagaratinam and Redman, 2005, p. 120). An important part of the value of a Delphi is that it helps avoid group pressures, and it can be used when definitive evidence is not available (Thanagaratinam and Redman, 2005, p. 122-123).

\section{Examples of the Use of the Delphi Method}

To get a better understanding of the DM, it is important to consider a number of examples of its use. The 'first applications of the Delphi method were in the field of science and technology forecasting' (Wikipedia). The objective of these Delphis was to combine expert opinions on the likelihood and expected development times of particular technologies in order to understand their probable development paths. 'Later the Delphi Method was applied in other places, especially those related to public policy issues, such as economic trends, health, and

W.E.; 3) 'Delphi Technique: A Step-by-Step Guide,' Haughey, Duncan; 4) 'The Delphi Method', Iqbal, Susanne and Pipon-Young, Laura. For a complete explanation of the Delphi method, the different types of Delphi, and how to use the Delphi method, see Keeney, Hasson and McKenna, 2011. 
education' (Wikipedia). One of these specialised health areas is obstetrics and gynaecology, an area that generates an array of problems that are complex and not easily explained. The Delphi Method has been found to be a particularly useful tool for developing group consensus in this area (Thangaratinam and Redman, 2005, p. 124). Another complex health related example is the 'use of a Delphi to predict how improvements in nutrition, family income, and prenatal care would impact on birth weight and subsequent intellectual development' (p. 122). Two other health related examples are: choosing performance measures for early psychosis treatment and using the opinions of a group of urologists to rate common treatments for men with enlarged prostate glands.

\section{Introducing Wisdom into the Analyses and Decision-Making Processes}

For all the reasons mentioned earlier, when the Delphi method is used in the kinds of situations which are favourable to it, it has demonstrated better results than conventional methods. So it makes sense to use the DM in these situations. It is arguably the smart thing to do. But would the analyses produced by using a proposed modified DM result in decisions characterised by greater wisdom? Not necessarily. The answer would only be yes if the participants (the experts) used were wiser than they had heretofore been. Unless the participants had become wiser, there is no reason to believe that the answer or solution deriving from using a modified DM would manifest an increase in wisdom. For the modified DM solution to have become wiser, the participants' opinions must have become wiser. And the only way for that to have happened is if, unlike in the past, the participants are now being selected for their demonstrated wisdom. For wiser decisions to result from the use of a modified DM, the participants should no longer simply be experts. They also need to be wise-perts, people who combine pertinent expertise with their wisdom. The upshot is that if we want wise analyses and decisions, we need to use modified DMs, DMs in which the procedures guarantee that the participants are wise-perts.

What can we expect from a wisdom oriented DM? If the solutions of the modified DMs are really wise ones, these will be the kinds of solutions that add to societal well-being, not just societal welfare. They will be solutions that are really right and best for the people affected, or for the affected organisations and societies. These wise solutions will certainly not be optimising solutions, solutions that attempt to maximise the utility of individuals or their organisations or their society. They will be solutions that are really better than the kind of solutions that are aligned with NE theory. Thus, the wisdom oriented DM can be an important tool, a tool that is an important part of a process of reducing the wisdom deficit, and thereby, genuinely improving the well-being of one's society.

Who are the wise people who would qualify and could then be chosen as wise-perts? In my view, there is no simple way to choose such people. There is no specific method or test that could reliably be used to identify them. However, the earlier discussion concerning the correlates of wisdom provides a way to think about this. In general, we would want to choose mature, older people who have realised many of their human development capabilities. Presumably we would like to choose people that have demonstrated a strong desire to make choices that are really in the best interests of groups like consumers, taxpayers and workers. We would want people who have strong positive convictions about improving people's health and the environment, as well as a strong concern for young people and the future of society. They should be people who are not biased toward their own self-interests. Obviously, the chosen people would need to have some specialised knowledge and expertise related to the problem or issue under consideration. Much more could be said along these lines. Certainly, the above does not mean that wise-perts would not have strong opinions about future societal 
directions. There is reason to believe, as the earlier DM discussion indicated, that the best results are likely to be obtained when the participants in a modified DM have strong, diverse opinions. When the latter is true, we are likely to have more confidence in the consensus solutions that are ultimately reached. In any case, there does not seem to be one best way to do this. Therefore, experimentation is necessary in order to discover what works.

\section{Putting the Proposal to Improve Wisdom in Perspective}

It is important to put the paper's proposal for dealing with the wisdom deficit in perspective. As Li Way Lee explained to me, when the DM process leads to wisdom, it is a little bit like the process of making whiskey: whiskey is distilled; it is not constructed. Also, wisdom is like a rainbow; you can see it and chase it, but you can't ever reach it! You just try to get closer to it. $^{2}$ There are good reasons why the proposed modified DM can help improve the economy's decision making wisdom. This is especially true when the modified (wisdom oriented) DM is used for proposed endeavours that can help deal with large-scale socio-economic dysfunctions. It is important to note that the purpose of the proposed DMs is to improve the process of analysis. If many wisdom-related DMs were accomplished, the full effect of them would not be realised until decisions incorporating the recommendations were made, followed by implementation. Also, there are presumably quite a few other things that could be done to improve the wisdom of decision making related to the functioning of the socio-economy. Further, to realise a society that functions more wisely, there would need to be broader societal changes. Positive changes in the functioning of economic institutions are more likely to occur if they are supported by citizens' overall appreciation of the importance of wisdom in society. Presumably there would be a need for organisations that support wisdom-increasing initiatives. And there would need to be a high level of societal aspiration for wisdom. The upshot is that even if well-functioning wisdom-related DMs were to become more prevalent, that would not be the ultimate solution to the wisdom deficit. Other things have to happen. But, hey, implementing wisdom related DMs would be a good, encouraging start.

\section{Conclusions}

To make wise choices about improving the well-being of the people in one's society, it is a dubious proposition to use the normative optimising procedures of neoclassical economics (NE). Neoclassical procedures are oriented to helping people choose in order to maximise their satisfaction given their actual preferences. Doing this does not help people make decisions that are really right and best for them. Too often important economic decision making in countries like the U.S. have reflected neoclassical maxims. The result has been unwise decision making. In other words, countries following these NE related procedures seem to have consistently experienced significant wisdom deficits. That is, their important economic decision making has too often not reflected people's true preferences. Neither has their decision making reflected ultimate truths about how best to live one's life, truths that are well understood by the great philosophers such as Aristotle and the great religious prophets such as Jesus Christ and Buddha. Their decision making also has not reflected important understandings about the potential that people can realise when their human development goes well.

This raises the question: is it possible to reduce such wisdom deficits by making important economic decisions with a greater dose of wisdom? This paper proposes one method for adding greater wisdom to the decision-making process when making large scale

\footnotetext{
${ }^{2}$ These insights are from Li Way Lee's email to me on October 11, 2018.
} 
public policy decisions. It is proposed to make these decisions using a modified version of the Delphi method. The standard DM has been a successful way that organisations and governments have utilised expert knowledge and opinions and have reached consensus solutions to significant problems and issues. The proposal of this paper is to incorporate wisdom in the decision making process by utilising DM participants who not only have relevant expertise but who have a record of demonstrated wisdom in decision making. There is good reason to believe that using such a modified Delphi method will lead to decisions that are really wiser than decisions made by the standard DM along with conventional decision making methods. The above proposal does not imply that wisdom cannot be added to decision making processes in other ways. Because there is reason to believe that the wisdom deficits of many societies are large and costly to people, the size and nature of these wisdom deficits should be investigated along with alternative ways to reduce them. People around the world would be much better off if the policymakers of their nations aspired to wisdom, not simply to narrow economic advantage.

\section{References}

Aquinas, Thomas (1948) Summa Theologica. New York: Benziger Brothers.

Beed, C. and Beed, C. (1999) "A Christian Perspective on Neoclassical Rational Choice Theory." International Journal of Socio-Economics, 26(4), pp. 501-520.

Biraima, M. H. (1998/1999) "From Rationality to Righteousness: A Universal Theory of Action." Humanomics, 14(4) and 15(1), pp. 206-261.

Erikson, Erik H. (1982) The Life Cycle Completed: A Review. New York: W. W. Norton.

Heukelom, Floris. (2014) Behavioral Economics: A History. New York: Cambridge University Press.

Kahneman, Daniel (2011) Thinking Fast and Slow. New York: Farrar, Straus and Giroux.

Kaplan, Justin D. (1958) "Nicomacheon Ethics." The Pocket Aristotle. New York: Washington Square Press.

Keeney, Sinead; Hasson, Felicity; and McKenna, Hugh (2011) The Delphi Technique in Nursing and Health Research. Oxford: Wiley-Blackwell.

Levinson, Daniel J. (1978) The Seasons of a Man's Life. New York: Ballantine Books.

McCloskey, Deirdre N. (2006) The Bourgeouis Virtues: Ethics for an Age of Commerce. Chicago, IL: University of Chicago Press.

McPherson, M. (1984) "On Schelling, Hirschman, and Sen: Revising the Conception of Self." Partisan Review, 51(2), 236-247.

Payutto, P. A. (1998) Buddhist Economics: A Middle Way for the Market. Bangkok, Thailand: Buddhadhamma Foundation.

Peterson, Christopher and Seligman, Martin E. P. (2004) Character Strengths and Virtues: A Handbook and Classification. Oxford: Oxford University Press.

Rescher, N. (1988) Rationality: A Philosophical Inquiry into the Nature and Rationale of Reason. Oxford: Clarendon Press.

Roberts, Robert C. and Wood, W. Jay (2007) Intellectual Virtues: An Essay in Regulative Epistemology. Oxford: Oxford University Press.

Schwartz, Barry and Sharpe, Kenneth (2010) Practical Wisdom: The Right Way to do the Right Thing. New York: Riverhead Books. 
Thaler, Richard H. (2015) Misbehaving: The Making of Behavioral Economics. New York: W.W. Norton.

Thangaratinam, Shakila and Redman, Charles W.E. (2005) "The Delphi Technique." The Obstetrician and Gynaecologist, 7, 120-125.

Tomer, John F. (2008) "Beyond the Rationality of Economic Man, Toward the True Rationality of Human Man." Journal of Socio-Economics, 37, pp. 1703-1712.

Tomer, John F. (2017) "Smart Persons and Human Development: The Missing Ingredient in Behavioral Economics." In Altman, Morris (Ed.) Handbook of Behavioural Economics and Smart Decision-making: Rational Decision-Making within the Bounds of Reason. Northampton, MA: Edward Elgar, pp. 137-154.

Turoff, Murray (1970) "The Design of a Policy Delphi." Technological Forecasting and Social Change, 2, pp. 149-171.

Yuengert, Andrew M. (2012) Approximating Prudence: Aristotelian Practical Wisdom and Economic Models of Choice. New York: Palgrave Macmillan.

Yuengert, Andrew M. (2014a) "It's Not So Bad to Have Limits, as Long as You Know Them: Economic Theory in Light of the Aristotelian Tradition." SSRN.com, May 4.

Yuengert, Andrew M. (2014b) "The Space Between Choice and Our Models of It: Practical Wisdom and Normative Economics." SSRN.com, June 27.

\section{SUGGESTED CITATION:}

John F. Tomer (2020) 'Economics' Wisdom Deficit and How to Reduce It.' Economic Thought, 9.2, pp.

24-37. http://www.worldeconomicsassociation.org/files/journals/economicthought/WEA-ET-9-2-Tomer.pdf 